\title{
Principias Manifestações Patológicas Identificadas em Edifícios de Paredes de Concreto na Região Metropolitana de Goiânia
}

\author{
Carlos Henrique. Azeredo ${ }^{1}$, Marcus. Mendes ${ }^{1 *}$, Matilde. Melo ${ }^{1}$, Wesley. Menezes ${ }^{1}$, \\ *Autor de Contacto: marcus.mendes@ifg.edu.br \\ ${ }^{1}$ NUCCTEC, Curso Bacharelado em Engenharia Civil, Instituto Federal de Goiás, Goiânia, Goiás
}

\begin{abstract}
RESUMO
O sistema construtivo de paredes de concreto foi empregado pela primeira vez no Brasil em 1979, mas normatizado no ano de 2012, a norma NBR 16055:2012. Este sistema tem sido utilizado em construção de unidades habitacionais de interesse social por propiciar, principalmente, maior produtividade de execução em relação aos sistemas construtivos mais usuais. Diante disso, o presente trabalho vistoriou 144 apartamentos em edifícios executados em paredes de concreto na região metropolitana de Goiânia, a fim de identificar as manifestações patológicas mais recorrentes nesse sistema, por meio o método proposto por Lichtenstein. Na análise dos resultados, constatouse que a maioria das manifestações patológicas tem origem por falha construtiva ou de execução, sendo a fissuração a patologia com maior incidência.
\end{abstract}

Palavras chave: Paredes de concreto; Manifestações patológicas; Diagnóstico; Inspeção. 


\section{INTRODUÇÃO}

Segundo Miranda (2011), o Brasil, no século XX, possuía um déficit habitacional de 5,5 milhões de moradias. Diante deste panorama, o Governo Federal buscou soluções para reduzir os fatores que influenciavam no aumento deste déficit, como a criação de programas de incentivo à construção de moradias. Com isso, no ano de 2009, foi criado o Programa Minha Casa Minha Vida (PMCMV) que foi viabilizado com parcerias entre a União, os Estados, os Municípios e os empreendedores, com o objetivo de facilitar o financiamento da compra de um imóvel por famílias de baixa renda. Este cenário nacional demandava a construção de moradias em larga escala, em tempo reduzido e com qualidade.

Nesse sentido, Leal (2010) relata que as construtoras precisaram buscar outros métodos construtivos, ao invés do convencional, para que fossem atendidos os requisitos exigidos pelo Programa Habitacional supracitado. As medidas, tais como padronização dos projetos com tipologias semelhantes, trabalho em escala, redução de desperdício de material e do tempo de execução de obra, foram alguns dos exemplos implantados pelas construtoras.

Como todo sistema construtivo, desde o convencional até os inovadores, o sistema de paredes de concreto também está sujeito ao surgimento de manifestações patológicas que podem ser resultantes de condutas inadequadas na concepção dos projetos, na elaboração dos projetos e na execução da obra. Isso se intensifica, principalmente, quando se trata de um sistema ainda não consolidado no país. Helene (1992) afirma que os fenômenos patológicos habitualmente apresentam manifestações externas, a partir da qual se pode deduzir a natureza, a origem e os mecanismos dos fenômenos envolvidos.

Nesse sentido, este trabalho teve como objetivo principal identificar as manifestações patológicas comumente recorrentes em uma obra destinada a habitação de interesse social de paredes de concreto e apresentar algumas condutas que possam mitigar essas manifestações patológicas, e, consequentemente, que resultem em edifícios mais duráveis e de melhor qualidade.

\section{REVISÃO DA LITERATURA}

As paredes de concreto foram empregadas pela primeira vez no Brasil no ano de 1979, no Estado de Minas Gerais, na Cidade de Santa Luzia, onde, segundo Sacht (2008), houve a construção de 46 casas pela Companhia de Habitação (COHAB), no Conjunto Habitacional Carreira Comprida. Corsini (2012) afirma que, apesar do sistema construtivo de paredes de concreto moldadas no local ter sido empregado no Brasil nessa época, o seu uso era pontual e em pequena escala de produção. Entretanto, na última década, houve o surgimento de uma demanda elevada no setor da construção em grande escala de produção, com a contribuição do programa de habitação do Governo Federal, o Programa Minha Casa Minha Vida (PMCMV).

O processo construtivo estava sendo empregado por poucas construtoras no Brasil, em razão da utilização de seus próprios conhecimentos e procedimentos de execução limitados. No entanto, àquelas que utilizavam, precisavam da aprovação de órgão certificadores, como o Sistema Nacional de Avaliações Técnicas (SiNAT), do Ministério das Cidades, que analisava o método construtivo e, se aprovado, concedia um Documento de Avaliação Técnica (DATec), visto que não havia normas regulamentadoras para a execução desse tipo de sistema (CORSINI, 2012).

A normatização dessa tecnologia entrou em vigor no país no ano de 2012 com a norma ABNT NBR 16055 (ABNT, 2012) que normatiza os requisitos e os procedimentos da parede de concreto moldada no local para a construção de edificações. Esta norma define as diretrizes básicas para construção das paredes de concreto moldadas no local, estabelecendo os requisitos de qualidade da 
estrutura, os critérios de projeto, das propriedades dos materiais a serem utilizados, do dimensionamento e dos procedimentos para a fabricação da parede, entre demais aspectos. De acordo com Signo (201-), a publicação dessa norma sucedeu com o início da inserção do PMCMV, o que certamente ajudou na rápida implantação do sistema.

A ABCP (2008), descreve o sistema de parede de concreto como um sistema construtivo racionalizado, cuja vedações da edificação e a estrutura são formadas por um único elemento construtivo, em que nele são embutidas as instalações elétricas e hidráulicas e as esquadrias. A ABNT NBR 16055 (ABNT, 2012) também define o sistema como sendo elementos estruturais autoportantes, que são moldados no local, e possuem comprimento maior que dez vezes sua espessura e que apresenta capacidade de suportar carga no mesmo plano da parede.

O elemento construtivo parede-laje, que é formada após a concretagem e retirada das fôrmas, representa um ciclo construtivo, e o resultado, depois da desforma, fornece uma parede pronta para receber os devidos acabamentos finais de acordo com o projeto do empreendimento.

Mitidieri, Souza e Barreiros (2012) destacam que problemas que podem surgir e diminuir a eficiência do sistema construtivo, devem ser verificados e solucionados, como os desaprumos, desníveis e outros. Estes impasses, por não serem previstos, além de aumentar o custo da obra, ocasiona atraso no cronograma, desperdícios de material e mão de obra.

\subsection{Componentes constituintes do sistema construtivo de paredes de concreto}

A qualidade de uma obra está diretamente ligada ao conhecimento acerca dos itens que integram o sistema construtivo, assim como os materiais a serem utilizados. Por esse motivo, será abordado, a seguir, cada componente que constitui o sistema de paredes de concreto com o objetivo de possibilitar um melhor entendimento de cada etapa do processo de produção, sendo que estes componentes podem ser vistos na Figura 1.

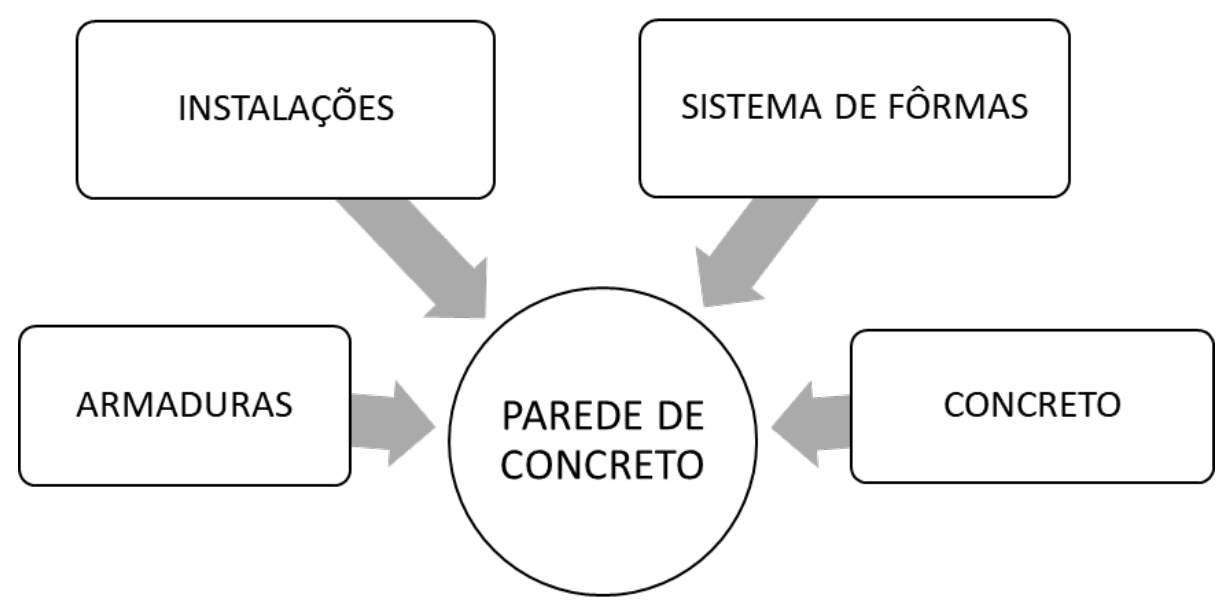

Figura 1. Componentes constituintes da parede de concreto

\subsubsection{Concreto}

Na Coletânea de Ativos 2011/2013 (ABCP, 2013), diz que, na visão dos especialistas, não há concreto convencional para paredes de concreto, pois há necessidade de execução de aditivos para atender aos diferentes requisitos da norma ABNT NBR 16055 (ABNT, 2015). Entre eles, cita-se a aceleração da produção por meio da redução do tempo de desforma, o que leva a aplicação da solução: uso de concretos convencionais com resistência característica a compressão (fck) acima 
do necessário à utilização do edifício. Mas, apesar disso, o concreto convencional é o segundo mais utilizado pelas construtoras para produção das paredes.

O tipo de concreto mais utilizado nesse sistema é o autoadensável que, segundo Tutikian (2004), esse tipo de material contém aditivos superplastificantes, os quais conferem alta plasticidade ao concreto fresco. O uso de concretos adensáveis nesse tipo de empreendimento propicia várias vantagens, tais como: exclusão do uso de vibradores para adensamento do concreto e, consequentemente, inexistência dos problemas inerentes ao seus uso irregular; redução do tempo de construção e redução da mão de obra no canteiro, visto que não é necessário executar a etapa de adensamento com vibradores; melhora no acabamento final da superfície da parede e da laje; maior liberdade em adaptar formas e dimensões, devido à alta trabalhabilidade; melhoria na segurança e saúde dos operários, devido à redução da operação no adensamento do concreto por parte da mão de obra; e redução do custo final do concreto e/ou da estrutura.

Um outro aspecto importante, de acordo com a ABNT NBR 16055 (ABNT, 2012), é um requisito complementar a ser analisado durante a execução: o controle do módulo de elasticidade do concreto, o qual permite definir as quantidades de dias necessários aos escoramentos dos concretos.

\subsubsection{Sistema de Fôrmas}

Conforme a NBR 16055 (ABNT, 2012), o sistema de fôrmas é um conjunto de peças composto de estruturas provisórias, cuja finalidade é moldar o concreto fresco. Suas peças compreendem os painéis de fôrmas, os escoramentos, cimbramento, aprumadores e andaimes, que inclui seus apoios, além das uniões que ligam os diversos elementos.

O tipo de material da fôrma a ser escolhido para moldar o concreto armado das paredes é fundamental para potencializar os ganhos do sistema construtivo de paredes de concreto e, além disto, o uso adequado deste, propicia o reaproveitamento das fôrmas e dos materiais utilizados para a sua construção (ABNT, 2012). Segundo a ABCP (2008), existem três tipos de materiais de fôrmas mais utilizados no sistema de parede de concreto, que são as: fôrmas metálicas de aço ou alumínio, fôrmas metálicas com chapas de madeira compensada e as fôrmas plásticas.

Missureli e Massuda (2009), afirmam que a escolha do tipo de material da fôrma e o aperfeiçoamento e detalhamento do projeto de fôrmas são de extrema importância para obter viabilidade no sistema construtivo e para conseguir melhor qualidade final.

Também é necessário a aplicação de desmoldante na face interna das placas das fôrmas, precedendo a fixação do sistema de fôrmas, , para facilitar a desforma sem danificar o sistema construtivo e possibilitar a reutilização da mesma. Nesse sentido, a NBR16055 (ABNT, 2012) considera que, devido à variedades de materiais de fôrmas, deve-se escolher o desmoldante específico para cada tipo de superfície, de modo que o concreto não fique aderente a fôrma e que não ocorra alteração nas características físicas e químicas deste. Além disso, o desmoldante não pode acumular resíduos na superfície da fôrma e da parede ou ser de difícil remoção ou degradar as superfícies dos painéis de montagem.

\subsubsection{Armaduras}

De acordo com Braguim (2013), o tipo de armadura a ser utilizado nas construções das paredes de concreto é um aspecto relevante para a viabilidade do sistema, já que uma das principais características deste é a produtividade, e, por esse motivo, deve-se usar telas soldadas simples ou telas soldadas duplas, levando em consideração o projeto estrutural. Ainda segundo o autor, para as telas soldadas simples uma única tela deve ser posicionada próximo ao eixo longitudinal da parede e para as telas soldadas duplas, duas telas devem ser utilizadas, sendo que cada uma é posicionada na face da parede, sem descumprir o cobrimento mínimo definido no projeto estrutural. Misurelli e Massuda (2009) relatam que, além da tela soldada ser posicionada no eixo vertical das paredes, nas bordas, nos vãos de portas e janelas, é necessário haver reforço de telas ou barras de 
armadura convencional. Os autores ainda afirmam que é importante a colocação de espaçadores plásticos para que o posicionamento das telhas e a geometrias dos painéis não tenham alteração durante a concretagem, além de garantir o cobrimento adequado.

\subsubsection{Instalações}

A NBR 16055 (ABNT, 2012) relata que qualquer componente embutido na parede de concreto deve ter seu formato preservado durante a concretagem e tolerar contaminações que possam afetar a sua integridade, a do concreto ou a da armadura. Ela também evidencia algumas moderações a serem consideradas nessas instalações, como a restrição do uso de instalações de tubulações horizontais, exceto em trechos não estruturais que possuam, no máximo, um terço do comprimento da parede, não podendo ultrapassar 1 metro. Da mesma forma, a norma enfatiza que nos encontros de paredes, em nenhuma hipótese é permitido instalar tubulações verticais e horizontais.

\subsection{Manifestações patológicas nas construções}

Tutikian e Pacheco (2013) afirmam que, para realizar um diagnóstico apropriado de uma manifestação patológica, é preciso fazer uma coleta de dados através de uma inspeção visual, com o propósito de identificar os sintomas observados, sua localização e sua intensidade.

Carmo (2003) afirma que os problemas patológicos de uma edificação normalmente estão relacionados à queda de desempenho da estrutura, que pode ocorrer devido aos danos e vícios construtivos que surgem no decorrer do seu tempo de uso. Além disso, Melo Júnior (2016) afirma que o desempenho de uma edificação se deve ao atendimento de todos os requisitos inerentes a ele, independente dos materiais e procedimentos usados para a construção.

O desempenho, de acordo com Iantas (2010), refere-se ao comportamento de cada material em serviço, ao longo da vida útil da edificação, e a sua medida relativa esperada no resultado do trabalho desenvolvido nas etapas de projeto, construção e manutenção. Ou seja, é a capacidade da estrutura da edificação em manter-se em condições íntegra de utilização durante a sua vida útil, não apresentando danos que comprometam em parte ou totalmente o uso para o qual está foi projetada.

Helene (1992) afirma que os problemas patológicos, exceto os casos singulares, podem apresentar manifestações externas com características individuais, possibilitando o entendimento de sua natureza, sua origem e os mecanismos envolvidos no fenômeno, assim como presumir as suas prováveis consequências. Ainda segundo o autor, esses sintomas, que também são intitulados como manifestações patológicas, podem ser analisados e classificados para orientar um primeiro diagnóstico, a partir de minuciosas observações visuais.

De acordo com norma de Inspeção Predial do Instituto Brasileiro de Avaliações e Perícias de Engenharia (IBAPE, 2012), as origens das patologias podem ser classificadas em: endógenas, as quais são originadas da própria edificação, provenientes de falhas ou irregularidades nas etapas de projeto e/ou execução, e que podem ser em função de falta de cumprimento das normas técnicas vigentes, da mão de obra desqualificada ou ainda pelo uso de materiais inadequados; exógenas, as quais são originadas por fatores externos a edificação e danos causados por terceiros; naturais, originadas por fatores relativos à fenômenos da natureza; e funcionais, originadas devido à degradação dos sistemas construtivos em função do envelhecimento natural e fim da vida útil da estrutura. Essa última pode ter como causas a exposição da estrutura ao meio agressivo em que ela está inserida, a ação humana, ou ainda a manutenção inadequada.

\section{METODOLOGIA}

\subsection{Características do objeto de estudo}


Os edifícios, objeto do estudo de caso, fazem parte de condomínios residenciais, composto por 28 blocos de quatro pavimentos tipos, com as mesmas características arquitetônicas. Nestes blocos, cada pavimento possui 4 apartamentos tipo com $35,66 \mathrm{~m}^{2}$ de área construída, resultando um total de $448 \mathrm{~m}^{2}$ de área de apartamentos construídos em paredes de concreto.

Entrando, desses 28 blocos, apenas 9 blocos foram selecionados para fazer parte do estudo de caso de inspeção, por serem blocos concretados em datas relativamente próximas e sem distinções significativa de equipe de trabalho e de sistemáticas diárias construtivas. Logo, foi traçado uma rota de inspeção nos 9 blocos, resultando em 144 apartamentos vistoriados.

O método de construção e as características dos materiais utilizados na obra para compor o sistema construtivo foram:

- fôrmas: utilizava-se de dois jogos de fôrma metálicas modulares, sendo que cada jogo representava um pavimento completo, ou seja, um jogo de fôrma representava quatro apartamentos mais o hall. Essas fôrmas já foram reutilizadas em outras obras da construtora e possuía uma espessura final das paredes de dez centímetros;

- armaduras: empregou-se telas soldadas de aço CA-50, com utilização de espaçadores para garantir a centralidade das mesmas;

- concreto: o concreto era usinado e apresentava um traço de fck 20, com agregado graúdo definido como brita 0 e fibra, apresentando um slump test de $10,0 \pm 2 \mathrm{~cm}$ e slump flow de $70,0 \pm 5 \mathrm{~cm}$. Esse concreto era aditivado após a chegada na obra com aditivo superplastificante;

- sistemas embutidos: a obra embutia às paredes de concreto a estruturação da parte elétrica (eletrodutos e caixas elétricas), que era fixada por fixadores amarrados à armadura e espaçadores, para garantir a sua centralidade na fôrma da parede;

- concretagem: a concretagem era realizada todos os dias, de segunda a sexta-feira, com poucas exceções da não ocorrência diária de concretagem.

- ciclo de concretagem: para cada jogo de fôrma, o ciclo era de 2 dias intercalados. Para cada ciclo, eram moldados 7 corpos de prova (CPs) para serem rompidos em 14h (3 CPs), 7 dias (2 CPs) e aos 28 dias (2CPs).

\subsection{Inspeções}

As concretagens dos blocos iniciaram no dia 30/07/2020 e foram realizadas diversas visitas técnicas na obra, com registros das inspeções visuais a partir do mês de novembro de 2020. Dessa forma, para o levantamento dos dados, foi elaborado uma ficha de inspeção visual.

Tinoco (2009) afirma que para uma adequada elaboração do mapa de danos é importante a utilização de fichas de identificação de danos durante a inspeção visual no edifício em estudo, a fim de registrar: a identificação do local da manifestação patológica, data da vistoria, caracterização do dano, causa, origem, ilustrações (foto e/ou desenho) e responsável pela coleta de informações. O modelo de ficha utilizada nesse trabalho permitiu os registros: data da vistoria; local (bloco e apartamento); responsável pela coleta; número do registro fotográficos; registro da fotografia; descrição da manifestação patológica; possíveis causas da patologia; diagnóstico; e proposta de conduta (terapia). Dessa forma, durante as visitas técnicas, forma realizados registros fotográficos das manifestações patológicas encontradas, bem como identificação das suas possíveis causas, observações e relatos dos responsáveis técnicos da obra.

Portanto, as s inspeções visuais foram realizadas nos primeiros meses após as concretagens, antes do início da fase de execução do revestimento das paredes de concreto. Dessa forma, foi possível verificar as manifestações patológicas iniciais nesse tipo de processo construtivo, sem interferências ou combinações com patologias oriundas de outros componentes construtivos. 


\subsection{Procedimento de coleta e análise de dados}

Adotou-se uma metodologia de inspeção mais objetiva e técnica conforme proposto por Lichtenstein (1986), a qual consiste em uma metodologia genérica para a resolução das patologias nas edificações, dividida em três etapas: levantamento de subsídios, diagnóstico da situação e definição de conduta, conforme Figura 2.

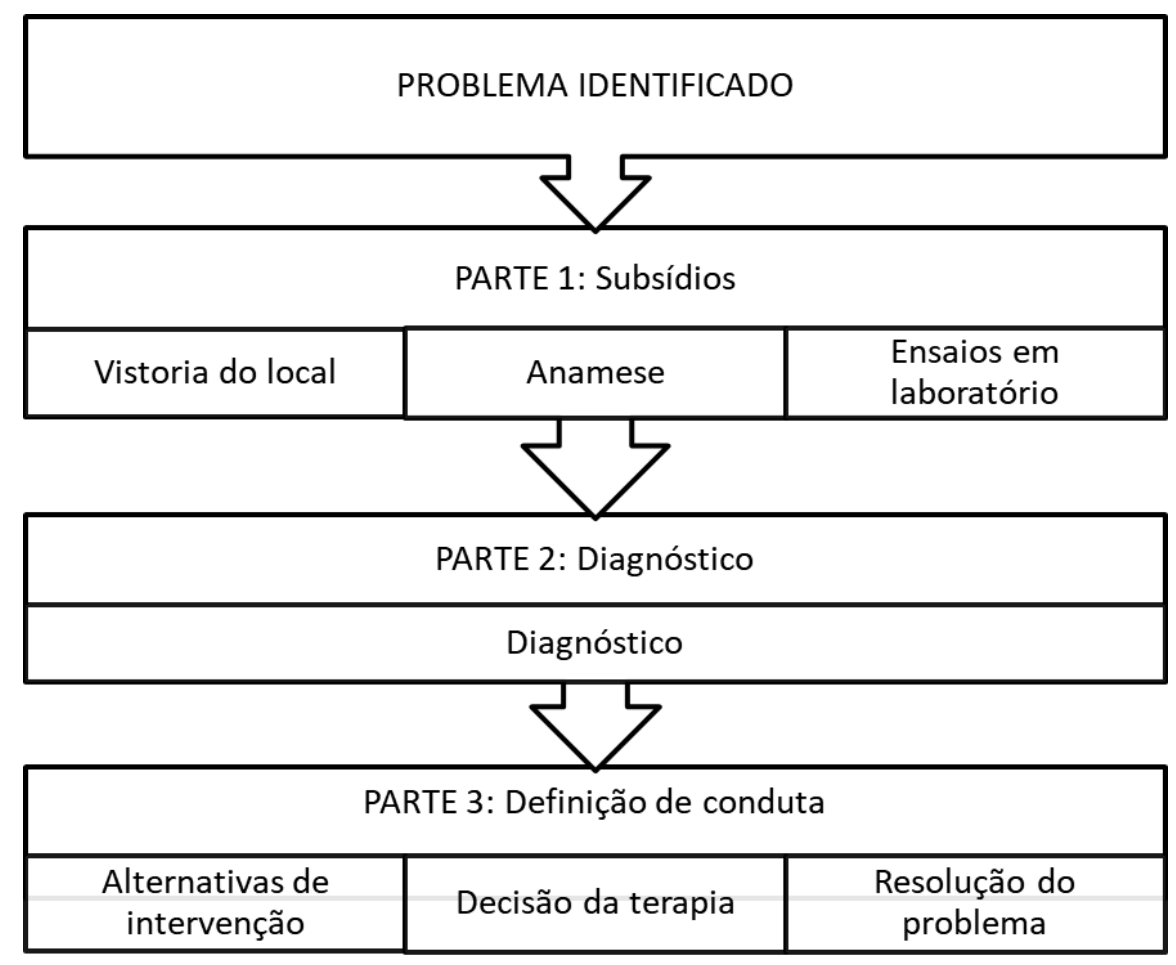

Figura 2: Fluxograma para resolução das patologias de acordo com Lichetenstein (1986)

\section{RESULTADOS E DISCUSSÃO}

A partir da análise dos registros das fichas, foram levantadas as principais manifestações patológicas encontradas nas paredes de concreto e suas prováveis origens. Esse levantamento está apresentado no Quadro 1.

Verificou-se que a maioria dos problemas encontrados são relativos à execução, devido, principalmente, à mão de obra desqualificada e à ausência de fiscalização na liberação das frentes de serviço. 


\begin{tabular}{|c|c|c|}
\hline \multicolumn{2}{|c|}{ MANIFESTAÇÃO PATOLÓGICA } & ORIGEM \\
\hline Aparecimento excessivo dos agregados do concreto & Material \\
\hline \multicolumn{2}{|c|}{ Falha de concretagem na parede do passa-prato } & Planejamento \\
\hline \multicolumn{2}{|c|}{ Falha de concretagem de paredes } & Execução \\
\hline \multicolumn{2}{|c|}{ Superfície do concreto mal acabada } & Execução \\
\hline Armaduras expostas & Execução \\
\hline Falhas em decorrência de tubulações e caixas embutidas & Execução \\
\hline \multirow{2}{*}{ Fissuração } & Fissuração horizontal nas paredes & Material \\
\cline { 2 - 3 } & Fissuração em vãos de janelas e portas & Execução \\
\cline { 2 - 3 } & Fissurações diversas na superfície do concreto & Execução \\
\hline
\end{tabular}

Quanto ao quantitativo percentual das origens (Figura 3), foi realizado a relação de surgimento das 9 manifestações patológicas encontradas, onde é verificado um percentual de $67 \%$ correspondente à execução. Vale ressaltar que, conforme é visto no Quadro 1 , as manifestações relacionadas à fissuração foram diferenciadas de acordo com a sua origem.

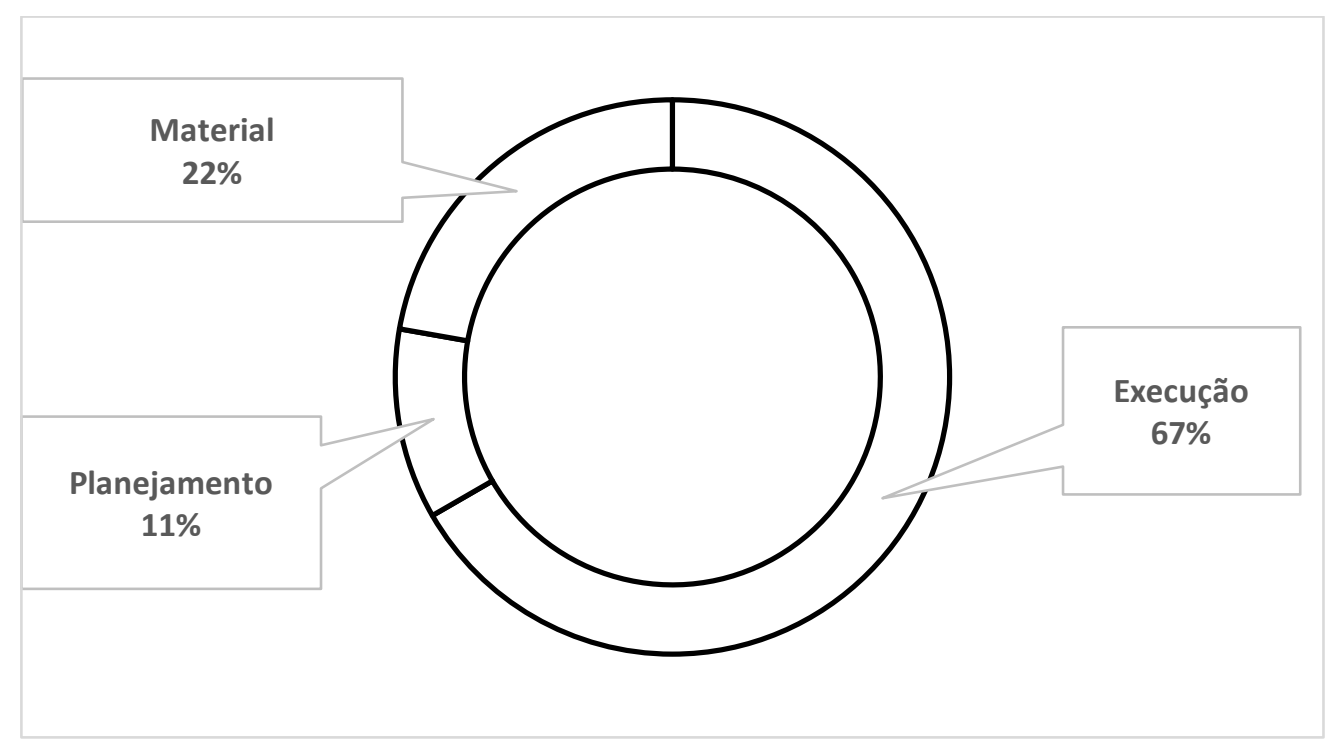

Figura 3 - Relação quantitativa das origens das manifestações patológicas

De acordo com o IBAPE (2012), pode-se classificar essa origem das manifestações como endógenas, ou seja, anomalias que provêm das falhas ou irregularidades nas etapas de projeto e execução, além da mão de obra desqualificada e pelo uso inadequado de materiais.

Em seguida, foi realizada uma análise percentual das incidências das manifestações apresentadas anteriormente, as quais estão apresentadas no Quadro 2. 
Quadro 2 - Número de incidências de cada manifestação patológica encontrada

\begin{tabular}{|c|c|c|}
\hline \multicolumn{2}{|r|}{ MANIFESTAÇÃO PATOLÓGICA } & QTDE (UND) \\
\hline \multicolumn{2}{|c|}{ Aparecimento excessivo dos agregados do concreto } & 26 \\
\hline \multicolumn{2}{|c|}{ Falha de concretagem na parede do passa-prato } & 36 \\
\hline \multicolumn{2}{|r|}{ Falha de concretagem de paredes } & 35 \\
\hline \multicolumn{2}{|r|}{ Superfície do concreto mal acabada } & 84 \\
\hline \multicolumn{2}{|r|}{ Armaduras expostas } & 27 \\
\hline \multicolumn{2}{|c|}{ Falhas em decorrência de tubulações e caixas embutidas } & 49 \\
\hline \multirow{3}{*}{ Fissuração } & Fissuração horizontal nas paredes & 35 \\
\hline & Fissuração em vãos de janelas e portas & 29 \\
\hline & Fissurações diversas na superfície do concreto & 43 \\
\hline \multicolumn{2}{|r|}{ TOTAL } & 364 \\
\hline
\end{tabular}

Observa-se, no Quadro 2, um quantitativo de 364 incidências das 9 manifestações patológicas identificadas nas 144 unidades habitacionais vistoriadas. Ainda assim, ressalta-se que todos os apartamentos inspecionados apresentaram alguma manifestação patológica.

Na Figura 4 está apresentada a incidência de cada manifestação patológica, referente à relação entre: a quantidade de ocorrências de cada tipo de patologia e o número de apartamentos vistoriados. A legenda no eixo x representa, ordenadamente, as manifestações (*):

A - Aparecimento excessivo dos agregados do concreto;

B - Falha de concretagem na parede do passa-prato;

C - Falha de concretagem de paredes;

D - Superfície do concreto mal-acabada;

E - Armaduras expostas;

F - Falhas em decorrência de tubulações e caixas embutidas;

$\mathrm{G}-$ Fissuras no concreto.

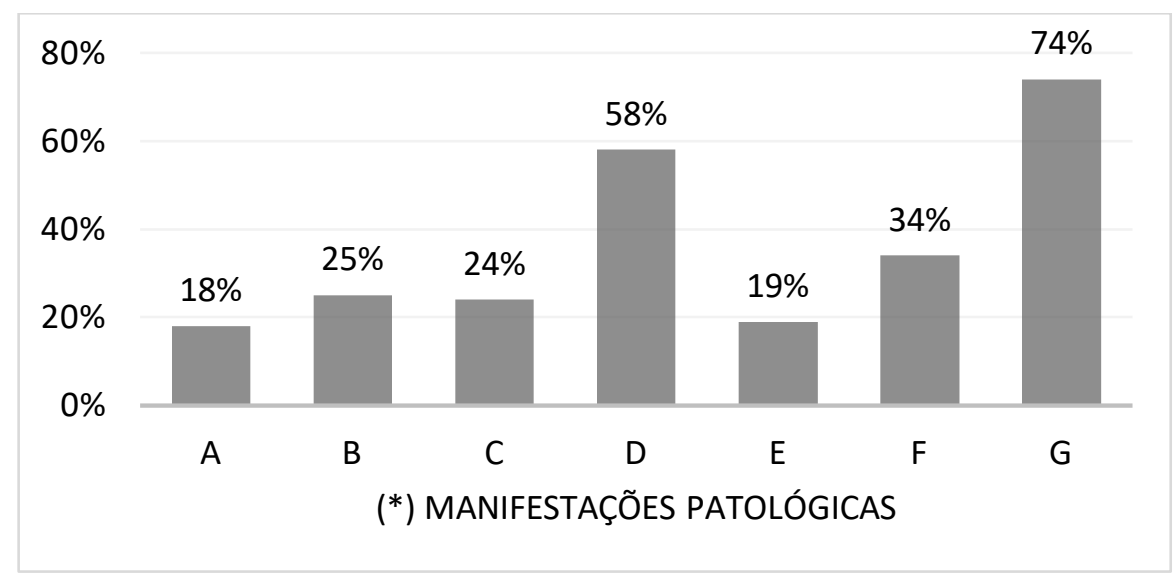

Figura 4 - Incidência (\%) das manifestações patológicas nos apartamentos

Na Figura 4, verifica-se que as maiores ocorrências (acima de 50\%) são referentes à superfície do concreto mal-acabadas e às fissuras no concreto. Em relação à superfície do concreto mal-acabada, 
$58 \%$ dos apartamentos apresentaram essa patologia, o que corrobora com a afirmação de Geyer (1995): "este dano é o mais recorrente em edifícios de paredes de concreto". Essa patologia poderia ser mitigada com a conferência mais rígida, por parte dos responsáveis técnicos da obra, na etapa de liberação dos serviços.

O total de incidências de fissurações foi de 107, o que indica que 74\% dos apartamentos possuíam algum tipo de fissuração. Em relação às fissuras, pode-se discretizar em três formas diferentes: fissuração horizontal nas paredes, fissuração em vãos de janelas e portas e fissurações diversas na superfície do concreto. Analisando isoladamente, tem-se a relação percentual conforme consta na Figura 5, cuja legenda no eixo x representa, ordenadamente, as manifestações de fissuração (*):

G1 - Fissuração horizontal nas paredes;

G2 - Fissuração em vãos de janelas e portas;

G3 - Fissurações aleatórias na superfície do concreto.

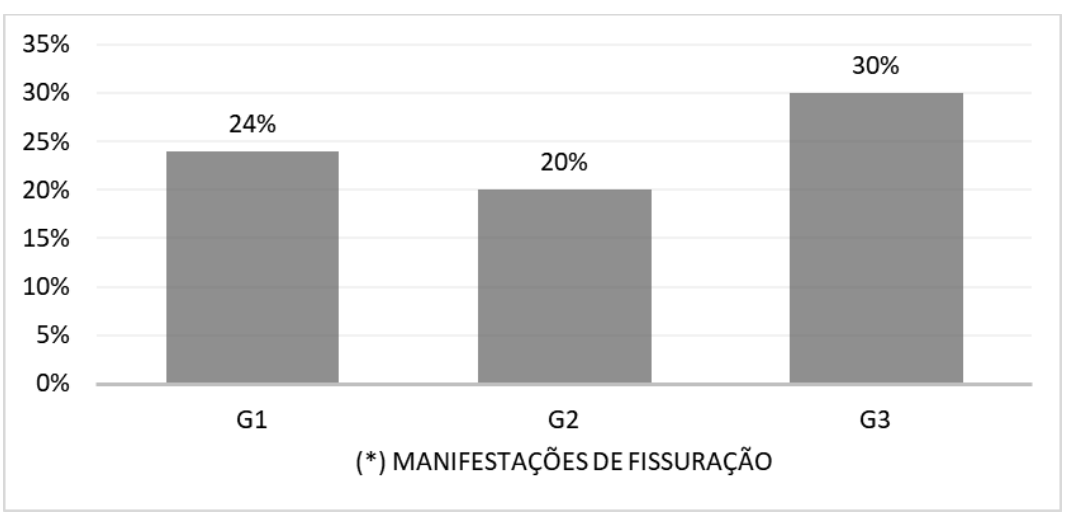

Figura 5. Incidência (\%) de tipos de fissurações

Observa-se que a média entre os 3 tipos de fissurações foi de $24,66 \%$, o que produz um desvio padrão foi igual a aproximadamente 0 . Portanto, não houve diferenças significativas entre o número de incidências dos 3 grupos de fissurações estudas, apesar das fissuras aleatórias sobressaírem à média em, aproximadamente, $5 \%$.

\section{CONCLUSÃO}

A partir das informações levantadas através das manifestações patológicas da obra estudada, verificou-se a necessidade de: uma implantação de controle na execução, verificando os materiais utilizados e sua correta utilização; e conferência da execução com os devidos projetos e controle de concretagem, verificando os dados e características do concreto, seu correto lançamento nas fôrmas, acompanhamento e conferência na desenforma. Essa necessidade advém da constatação da falha significativa por parte dos responsáveis técnicos do canteiro, na liberação e recebimento de frentes de serviço.

Portanto, constatou-se que 67,0\% das manifestações encontradas são relativas à execução, vinculada a falha de conferência.

Observa-se que uma solução mitigadora para esse problema é: a construtora deve possuir um plano de ação com a equipe de obra, de modo a minimizar ou eliminar o surgimento das manifestações patológicas, a fim de que ela possa usufruir das vantagens que o sistema construtivo de paredes de concreto oferece. Pode-se citar, como exemplo: treinar constantemente a equipe e capacitá-la tanto para execução como para acompanhamento e verificação dos serviços executados e a se executar. Dessa maneira pode-se aumentar a probabilidade de uma construção com qualidade e assegurar que possíveis manifestação advindas da execução tenha pouca ou nenhuma frequência. 
Apesar das maiores manifestações patológicas serem referentes a fissuração, neste caso específico em estudo, essas falhas foram ocasionadas por algum problema de execução. Entretanto, há condições e técnicas eficientes de maneira que não aconteça o surgimento de problemas significativos como àqueles da obra analisada.

Assim sendo, pode-se concluir que não é pelo fato de uma obra ser feita de paredes de concreto que, obrigatoriamente, irá apresentar alguma manifestação patológica. Ressalta-se que qualquer obra deve buscar constantemente resultados de qualidade do seu produto para a entrega dos clientes finais, sendo estes os que garantem a boa imagem repassada pela construtora.

\section{REFERENCIAS}

Associação Brasileira de Cimento Portland - ABCP (2008). Paredes de concreto: coletânea de ativos 2007/2008, São Paulo.

Associação Brasileira de Cimento Portland - ABCP (2010). Paredes de concreto: coletânea de ativos 2009/2010, São Paulo..

Associação Brasileira de Cimento Portland - ABCP (2013). Paredes de concreto: coletânea de ativos 2011/2013, São Paulo.

Associação Brasileira de Normas Técnicas - ABNT (2013). NBR 15575-1. Edificações habitacionais - Desempenho - Parte 1: Requisitos gerais. Rio de Janeiro.

Associação Brasileira de Normas Técnicas - ABNT ( 2012)NBR 16055. Parede de concreto moldada no local para a construção de edificações - Requisitos e procedimentos. Rio de Janeiro.

Braguim, T. C. (2013) “Utilização de modelos de cálculo para projeto de edifícios de paredes de concreto armado moldadas no local". 2013. 227f. Dissertação de Mestrado em Engenharia CivilEscola Politécnica da Universidade de São Paulo, São Paulo.

Carmo, P. O. (2003). “Patologia das construções". Programa de atualização profissional - CREA, Rio Grande do Sul.

Corsini, R. (2012). Paredes Normalizadas. Revista Téchne, São Paulo, n. 183.

Geyer, A. L. B. (1995). "A melhoria da qualidade das superficies do concreto através da drenagem com fôrmas revestidas internamente por um geotêxtil”. 1995. 148f. Dissertação de Mestrado em Construção Civil - Universidade Federal do Rio Grande do Sul, Porto Alegre.

Helene, P. R. L. (1992). “Manual prático para reparo e reforço de estruturas de concreto”. $2^{\circ}$ ed. São Paulo: Editora Pini,

Iantas, L. C. (2010). "Estudo de caso: análise de patologias estruturais em edificações de gestão pública”. 2010. 58f. Monografia de Especialista em Construção de Obras Públicas Universidade Federal do Paraná, Curitiba.

Instituto Brasileiro de Avaliações E Perícias De Engenharia - IBAPE (2012) Norma de Inspeção Predial Nacional. São Paulo. 
Leal, U. (2010) Três não é demais. Construção e Mercado, São Paulo: Pini, n. 109, p. 20-24, agosto.

Lichtenstein, N. B. (1986). “Patologia das construções: boletim técnico n. 6.” São Paulo: EPUSP.

Melo Júnior, C. M. (2016) "Metodologia para geração de mapas de danos de fachadas a partir de fotografias obtidas por veículo aero não tripulado e processamento digital de imagens”. 2016, 376f. Tese de Doutorado em Estruturas e Construção Civil - Universidade de Brasília, Brasília.

Misurelli, H., Massuda, C. (2009). Como construir Paredes de Concreto. Revista Téchne, São Paulo, ed. 147, ano 17, n. 147, p. 74-80, jun.

Miranda, T. (2011). "Déficit habitacional no brasil é de 5,5 milhões de moradias". CÂMARA DOS DEPUTADOS, 2011. Disponível em: <https://www.camara.leg.br/noticias /213505-deficithabitacional-no-brasil-e-de-55-milhoes-de-mor adias/ >. Acesso em: 28 nov. 2019.

Mitidieri, C. V.; Souza, J. C S..; Barreiros, T. S.(2012) "Sistemas construtivo de paredes de concreto moldadas no local: aspectos do controle de execução". In: Congresso Brasileiro do Concreto, 54., 2012, Maceió. Anais. São Paulo: IBRACON, 2012. p. 01-08. Disponível em: < https://www.ipt.br/centros_tecnologicos/CETAC/artigos_tecnicos/431-

sistema_construtivo_de_paredes_de_concreto_moldadas_no_local:_aspectos_do_controle_de_ex ecucao.htm>. Acesso em: 12 out. 2019.

PiancastellI, E. M. (2019). Patologias do concreto. AECweb, 201-. Disponível em: $<$ https://www.aecweb.com.br/cont/m/rev/patologias-do-concreto_6160_10_0/>. Acesso em: 28 nov. 2019.

Sach, H. M. (2008). "Painéis de vedação de concreto moldados in loco: avaliação de desempenho térmico e desenvolvimento de concreto". 2008. 286f. Dissertação de Mestrado em Arquitetura e Urbanismo - Escola de Engenharia de São Carlos, São Carlos.

Signo, A. F. J. (2019). "Por que Parede de Concreto? Núcleo Parede de Concreto", 201-. Disponível em: < http://nucleoparededeconcreto.com.br/artigos/por-que-parede-de-concreto $>$. Acesso em: 12 out. 2019.

Tinoco, J. E. L.. (2009). “Mapa de danos: Recomendações básicas”. Centro de estudos avançados da conservação integrada - CECI. Olinda, Pernambuco,2009, vol. 43. 23p.

Tutikian, B. F. (2004). "Método para dosagem de concretos auto-adensáveis". 2004. 149f. Dissertação de Mestrado em Engenharia Civil - Universidade Federal do Rio Grande do Sul, Rio Grande do Sul..

Tutikian, B., Pacheco, M. (2013). “Inspeção, Diagnóstico e Prognóstico na Construção Civil”. Boletim Técnico da Alconpat Brasil. Mérid. 